\title{
Muti-wheel Bogie Braking System Simulation of Civil Aircraft
}

\author{
Hua-wei $\mathrm{Wu}$ \\ School of Information Science and Engineering \\ Central South University \\ Changsha, China, 410083 \\ whw_xy@163.com \\ Lin-feng Wang \\ State Key Laboratory of Powder Metallurgy \\ Central South University \\ Changsha, China, 410083 \\ wanglfcsu@163.com
}

\author{
Te-fang Chen \\ School of Information Science and Engineering \\ Central South University \\ Changsha, China, 410083 \\ Wei-ming Huang \\ State Key Laboratory of Powder Metallurgy \\ Central South University \\ Changsha, China, 410083
}

\begin{abstract}
In order to meet the development needs of large civil aircraft, this paper takes four-wheel bogie landing gear as example and introduces the muti-wheel braking system control mode and control law. The kinematics of aircraft braking process and the mathematical models of wheels, tyres and runway, hydraulic servo valves, brakes, etc. are analyzed. Yaw movement is introduced on the basis of the original three degrees of freedom movement. The multi-wheel simulation system based on fuzzy control with "I" mode is established. Five common landing states of muti-wheel aircraft are simulated, results show the control parameters are real-time adjust to make full use of runway friction force, the overall braking effect is desirable. Thus it provides an insightful new way of thinking for successful development of multi-wheel bogie aircraft braking system in integrated environment.
\end{abstract} ratio

Keywords-bogie; muti-wheel; Simulation; braking system; slip-

\section{INTRODUCTION}

In order to reduce the pressure of pavement and to improve maneuverability, the multi-wheel bogie, which has two styles of four-wheel and six- wheel, is generally adopted to be as the main landing gear structure of large aircraft, such as A340, A380, B747, B757, B767, B777, and so on. Due to differences in loads and runway status, the multi-wheel bogie structure is more complex than a single-wheel structure, and more difficult to control [1]-[2]. In this paper, the control mode, the control law, and the braking process model of multi-wheel braking system are analyzed. The muti-wheel braking system simulation model is established in the MATLAB/Simulink environment. Five common landing states of muti-wheel aircraft are simulated: loads and runway status are same, runway status is different, load of inside and outside wheel are different, load of left and right wheel are different, load and runway status are different. The results show that the "I" Fuzzy Control mode based on slip-ratio meets the requirements of the multi-wheel braking system.

\section{MUTI-WHEEL BOGIE BRAKING SYSTEM}

The purpose of aircraft ABS is to prevent the wheels from locking, avoid tyre excessive wear or blasting, and take advantage of the maximum friction of the pavement to achieve smooth and efficient braking.

\section{A. The Four-wheel Bogie Layout}

Figure 1 shows the four-wheel bogie layout of the typical large civil aircraft. The front wheels without braking are only effected by the rolling friction force during braking process.

$$
\text { Front wheel }
$$

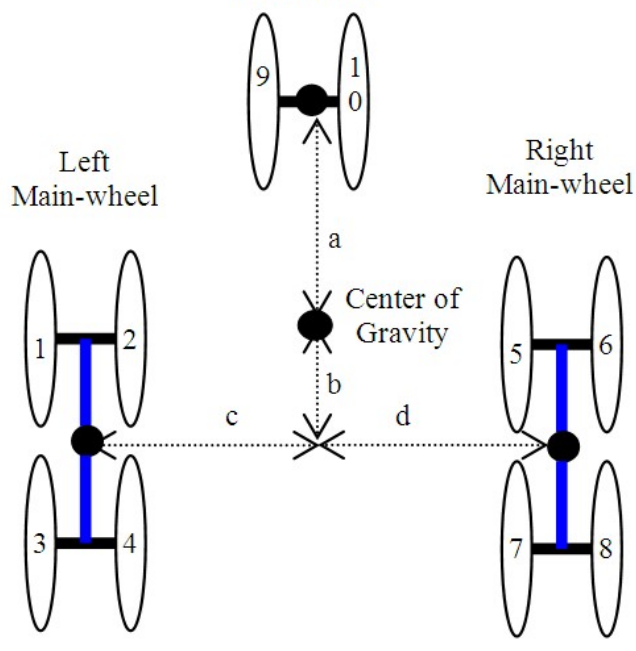

Figure 1. Layout of the mutiwheel

\section{B. The Control Mode}

Individual wheel control "I" mode and the paired/grouped wheel control "PG" mode are the two common control modes of the aircraft braking system [3]-[4].The "I" mode: the wheel is separately controlled to make full use of the ground friction 
forces, and this mode has been basically adopted by the mature advanced civil aircraft. The "PG" mode: the braking wheels are controlled in pairs, that is, two or more implementing agencies are controlled by a signal. This control mode is simple, but the braking efficiency is not high. When a wheel failure, the pressure of the paired wheel will be released simultaneously, which likely results in the tyre excessive wear and yaw. This control mode is usually used in alternate braking system or emergency/parking braking system.

Recently, the "I + PG" mode has gradually become the mainstream braking control mode of the Airbus and Boeing's civil aircraft. That is, the normal braking system adopts "I" mode, alternate/emergency braking system adopt "PG" mode. It assures that the system has high safety and reliability as well as good economic and efficiency

\section{MATHEMATICAL MODELS}

\section{A. The Aircraft Braking Force Model}

When taxiing, the yaw movement is considered based on the conventional three degrees of freedom [5]-[8], so the aircraft movement is simplified to four aspects such as the course direction, the vertical direction, pitching, yawing. Figure 2 shows the force states of the aircraft during landing.

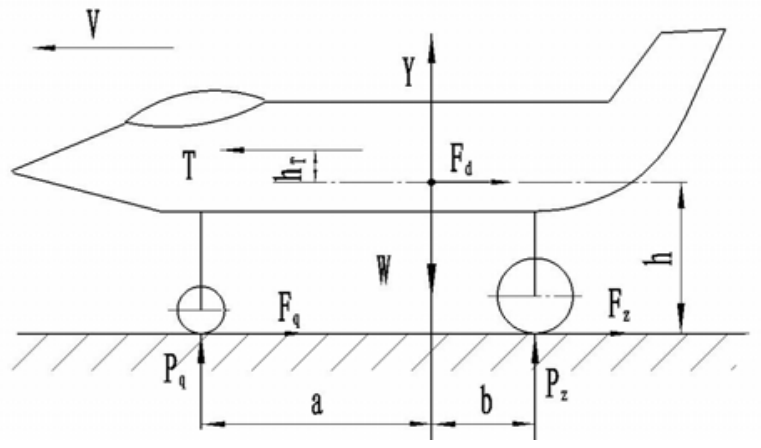

Figure 2. Force acting on the aircraft during landing

$$
\begin{aligned}
& \frac{W}{g} \cdot \dot{V}=T-F_{d}-F_{Z}-F_{q} \\
& W=Y+P_{Z}+P_{q} \\
& P_{q} \cdot a=P_{Z} \cdot b+\left(F_{Z}+F_{q}\right) h+T \cdot h_{T}
\end{aligned}
$$

The friction force of front wheel $F_{q}$ and the engine thrust $T$ :

$$
\begin{aligned}
& F_{q}=P_{q} \cdot \mu_{g d} \\
& T=k_{t} \cdot V^{2}
\end{aligned}
$$

The load $P_{Z}$ and friction force $F_{Z}$ of main wheel:

$$
\begin{aligned}
P_{Z} & =P_{Z L}+P_{Z R}=\sum_{i=1}^{n} P_{Z L_{i}}+\sum_{i=1}^{n} P_{Z R_{i}} \\
F_{Z} & =F_{Z L}+F_{Z R}=\sum_{i=1}^{n} F_{Z L_{i}}+\sum_{i=1}^{n} F_{Z R_{i}} \\
& =\sum_{i=1}^{n} P_{Z L_{i}} \cdot \mu_{Z L_{i}}+\sum_{i=1}^{n} P_{Z R_{i}} \cdot \mu_{Z R_{i}}
\end{aligned}
$$

The aircraft aerodynamic lift $Y$ and the aerodynamic $\operatorname{drag} F_{d}$ :

$$
\begin{aligned}
& Y=\frac{1}{2} \rho C_{Y} S V^{2} \\
& F_{d}=\frac{1}{2} \rho C_{X} S V^{2}
\end{aligned}
$$

The torque restrictive equation without yawing:

$$
P_{Z L} \cdot c+P_{Z R} \cdot d \leq P_{q} \cdot u_{g z} \cdot a
$$

Where: $W$ is the weight of aircraft. $g$ is acceleration of gravity. $k_{t}$ is the engine thrust coefficient. $n$ is the number of the braked wheels. $V$ is aircraft speed. $P_{q}$ is the front wheel loads. $\rho$ is the air density of the landing airport. $C_{X}, C_{Y}$ are aircraft aerodynamic lift and drag coefficient. $S$ is the wing area. $\mu_{g d}, \mu_{g z}$ are the front wheel rolling friction coefficient and the lateral friction coefficient. $a, b$ respectively are the distances of the front and main landing gear center from CG. $c$, $d$ respectively are the distance of the left and right main landing gear center from CG. $F_{Z L}, F_{Z R}$ are the friction forces of the left and right main landing gears. $h_{T}$ is the thrust horizontal height from center of gravity. $h$ is the height of CG.

\section{B. Wheel Model}

The forces acting on a wheel during landing are shown in Figure 3, the kinetic equation as follows:

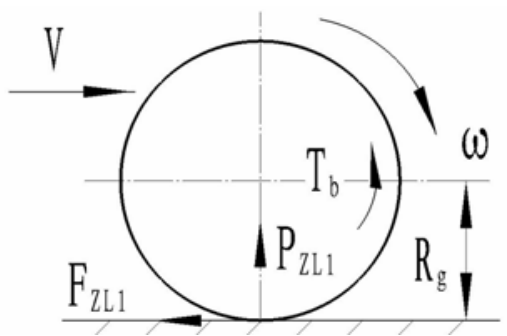

Figure 3. Forces acting on a braked wheel

$$
\begin{aligned}
& J \cdot \omega=F_{Z L_{1}} \cdot R_{g}-M_{b r k} \\
& F_{Z L_{1}}=\mu \cdot P_{Z L_{1}} \\
& \sigma=\left(V-\omega \cdot R_{g}\right) / V
\end{aligned}
$$

Where: $J$ is the wheel moment of inertia. $\omega$ is the angular velocity of main wheel. $M_{b r k}$ is the wheel braking torque. $R_{g}$ is the tyre rolling radius. $P_{Z l l}$ is the vertical reaction force.

\section{Hydraulic Servo Valve Model}

According to the actual experiments, it may be consider that the dynamic characteristics of the hydraulic servo system are determined by the electro-hydraulic pressure servo valve. So, the hydraulic servo system is considered as a Second-order Oscillating Link.

$$
G(s)=\frac{k_{v} \cdot \omega_{\mathrm{n}}^{2}}{S^{2}+2 \xi \cdot \omega_{\mathrm{n}} \cdot S+\omega_{\mathrm{n}}^{2}}
$$

Where $k_{v}$ is the servo valve gain. $\omega_{n}$ is the natural frequency of the servo valve. $\xi$ is the damping of the servo valve. 


\section{Brakes Model}

The Brakes transform the braking pressure into the braking torque, which is composed of the cylinder seat, rotor disks, stator disks and so on. When braking, the pressure is applied from servo valve to impacted disk, for squeezing each other, the braking torque between the static and rotor disk is generated, which leads to the kinetic energy is converted into heat energy released. The braking torque is closely related to the braking thrust, the friction properties of the material, the number of friction surfaces and so on.

$$
M_{b r k}=\mu_{m c} \cdot N_{m c} \cdot S_{t} \cdot\left(D_{s}+d_{s}\right) / 4
$$

Where: $N_{m c}$ is the numbers of friction surface. $\mu_{m c}$ is the material friction coefficient. $S_{t}$ is the axial force acting on brakes. $D_{s}, d_{s}$ are the brake disk outside and inside diameter.

\section{E. Runway condition and Tyre Model}

The friction force between the tyre and ground is the master factor during landing braking, in the case of certain load, the friction coefficient influenced by many factors such as aircraft speed, slip-ratio, the vertical load, the tyre condition, the runway surface condition, etc. Among them, the slip-rate and runway surface condition are most complex with the largest effect. Figure 4 shows a typical relation between the friction coefficient $\mu$ and the slip-ratio $\sigma$ on diverse runway.

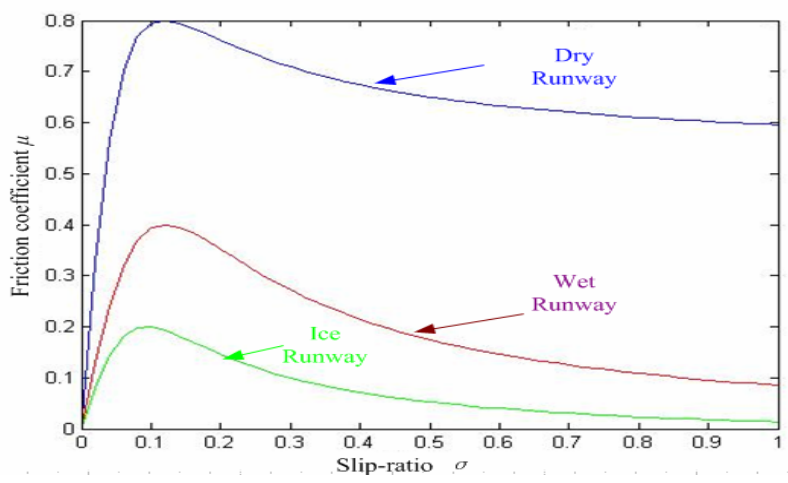

Figure 4. Friction coefficient vs. slip-ratio

To reduce the amount of computation, according to the characteristics of the braking system the simplified Magic Formula [5]-[7],[9] is used as the model of he longitudinal friction coefficient and slip-ratio, as (9).

$$
\mu=D \cdot \sin (C \cdot \arctan (B \cdot \sigma))
$$

Where: $D$ is peak factor indicating the maximum of the curve. $B$ is the stiffness factor. $C$ is the curve shape factor.

\section{F. Fuzzy control model}

The fuzzy control has gradually been applied in the braking systems of aircraft because of the features of strong robustness and imprecise reasoning [10]-[12]. According to the civil braking system operating principle, the "I" mode fuzzy control based on slip-ratio with runway identification is achieved. The slip-ratio error and its change rate are chosen as input variables, and the braking pressure is chosen as the output variable, shown in figure 5 .

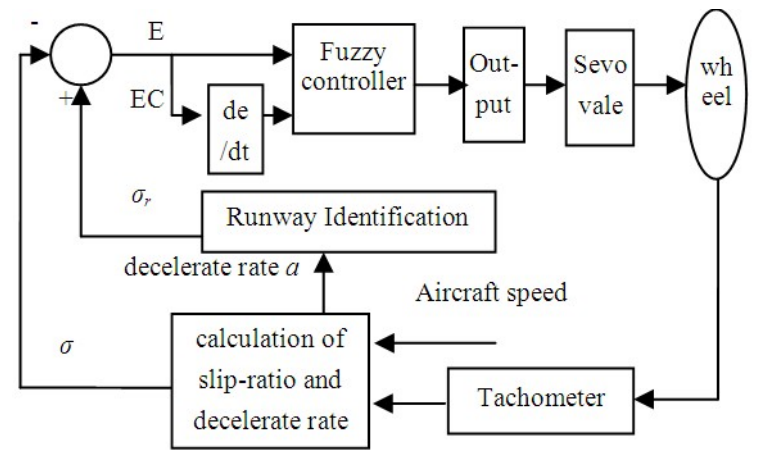

Figure 5. Schematic of fuzzy control

Slip-ratio error is defined as the difference of the real-time slip-ratio and the desire slip-ratio, $E=\sigma_{r}-\sigma$, the error change rate $E C=d e / d t$, the braking pressure variable is $U$. The domains of $E, E C, U$, are respectively set to [-2 2], [-5 5], [0 1]. Their fuzzy subsets are the same form $\{N B, N S, Z E, P S, P B\}$, the "tirmf" function is selected as the membership function.

TABLE I. RULE OF FUZZY CONTROL

\begin{tabular}{|c|c|c|c|c|c|}
\hline \multirow{2}{*}{ EC } & \multicolumn{5}{|c|}{$\mathbf{E}$} \\
\cline { 2 - 6 } & $\boldsymbol{N B}$ & $\boldsymbol{N B}$ & $\boldsymbol{Z E}$ & $\boldsymbol{P S}$ & $\boldsymbol{P B}$ \\
\hline NB & NB & NB & NS & NS & ZE \\
\hline NS & NB & NS & NS & ZE & PS \\
\hline ZE & NS & NS & ZE & PS & PS \\
\hline PS & NS & ZE & PS & PS & PB \\
\hline PB & ZE & PS & PS & PB & PB \\
\hline
\end{tabular}

IV. Simulation

In the MATLAB / Simulink environment, the multi-wheel braking system simulation model is established, which is composed of the braking force model and four individual wheel models. The Individual wheel model is composed of hydraulic servo valve model, brake model, runway and tyre model and fuzzy controller model. Figure 6 and 7 show the individual wheel and system simulation model.

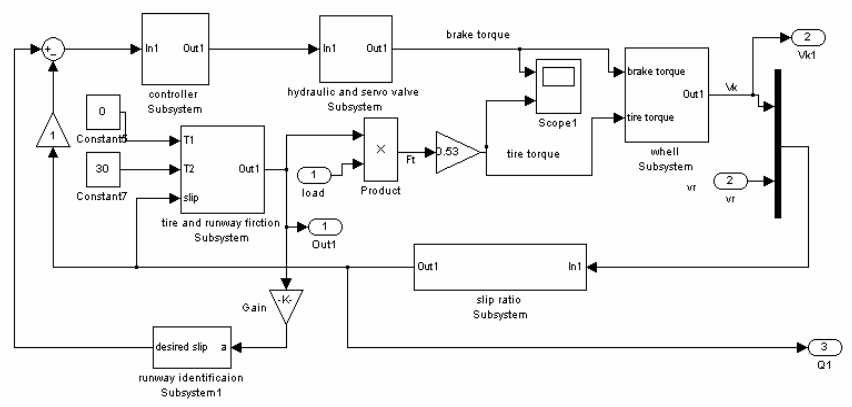

Figure 6. Simulation model of the individual wheel

For the convenience of the study, the eight main wheels are divided into the corresponding four groups: $\operatorname{Left}$ front $(1,2)$, Left-rear(3,4), Right-front(5,6), Right-rear(7,8); or Left-outside $(1,3)$, Left-internal(2,4), Inside-right $(5,7)$, Right-outside(6,8), 
shown as figure1. Five common landing states of muti-wheel aircraft are simulated. Simulation results are shown in figure 8 to 12.Some important parameters are shown in table II .

\section{Muti-wheel Aircraft-ABS Simulink Model}

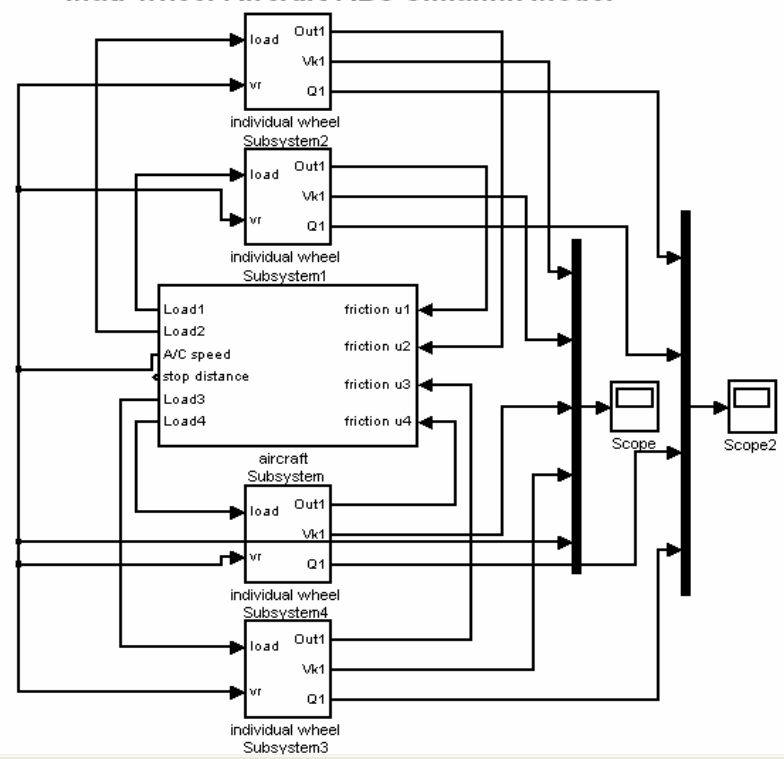

Figure 7. Simulation model of the muti-wheel braking system

TABLE II. SOME IMPORTANT PARAMETERS USED

\begin{tabular}{|c|c|c|c|c|c|}
\hline Parameter & Value & Unit & Parameter & Value & Unit \\
\hline$W$ & 62 & $\mathrm{~T}$ & $n$ & 4 & \\
\hline$P$ & 8 & $\mathrm{MPa}$ & $\mu_{g d}, \mu_{g z}$ & 0.05 & \\
\hline$I$ & 2.88 & $\mathrm{Kg} \cdot \mathrm{m}^{2}$ & $R_{g}$ & 0.53 & $\mathrm{~m}$ \\
\hline$\omega_{0}$ & 117 & $\mathrm{rad} / \mathrm{s}$ & & & \\
\hline
\end{tabular}
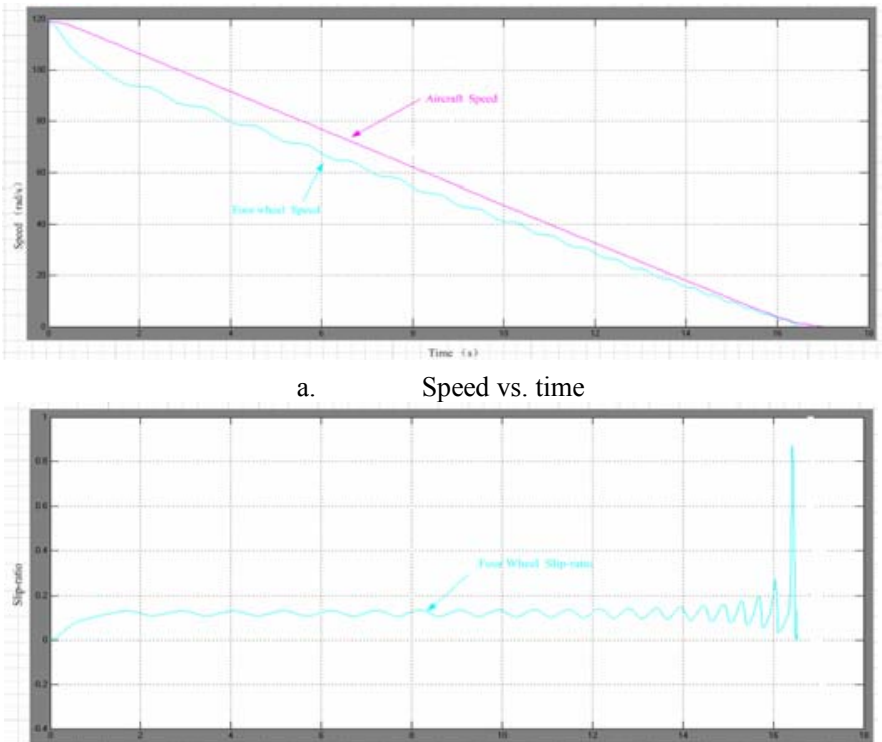

b.

Slip-ratio vs. time

Figure 8. Simulation results of the same load and runway status
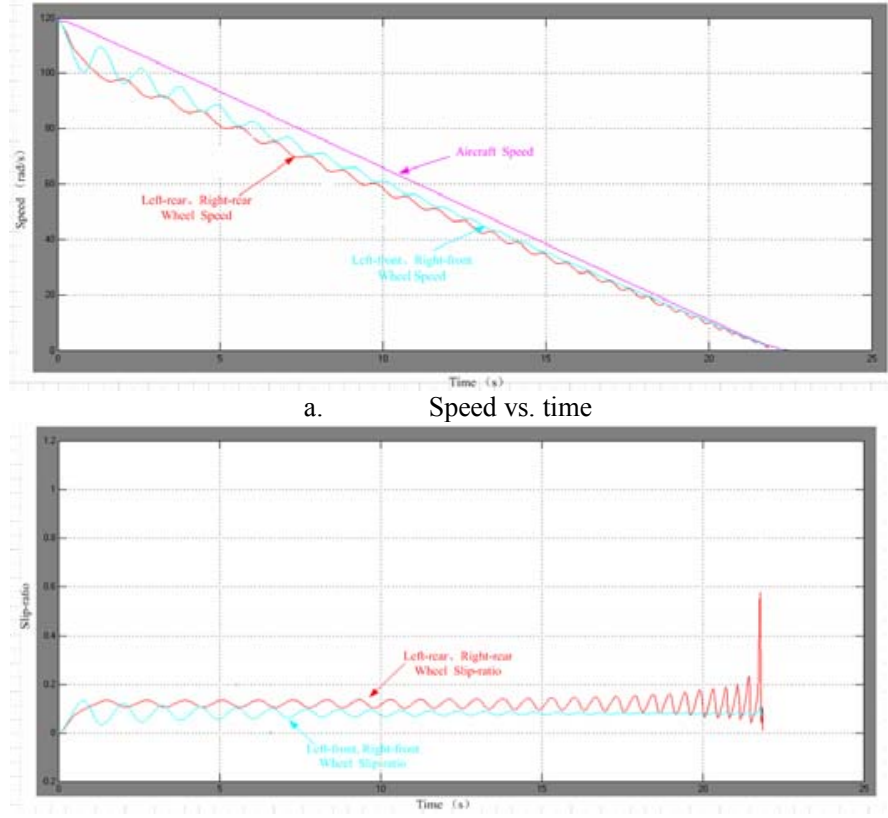

b. Slip-ratio vs. time

Figure 9. Simulation results of the different runway status

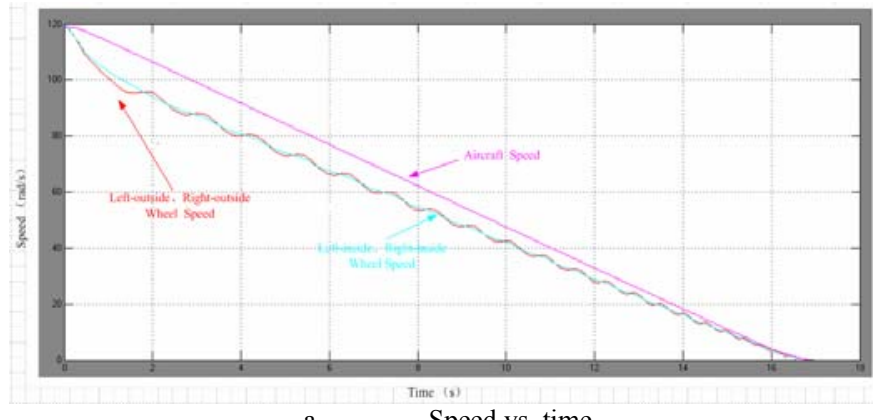

Speed vs. time

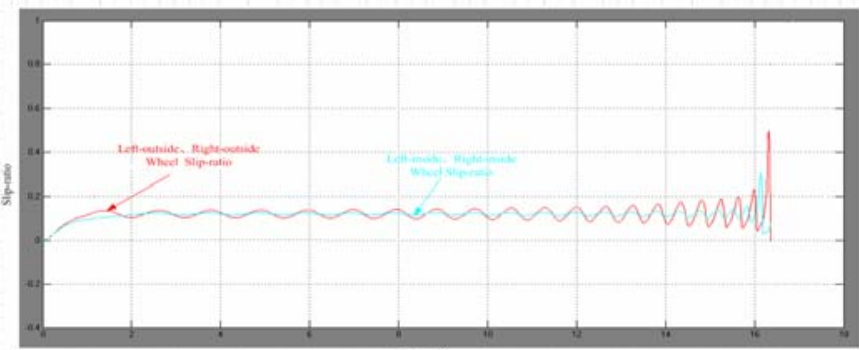

b. Slip-ratio vs. time

Figure 10. Simulation results of different load in outside and inside

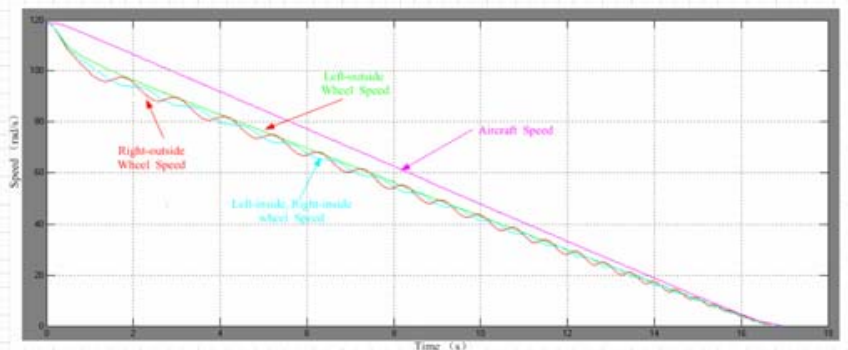

a. $\quad$ Speed vs. time 


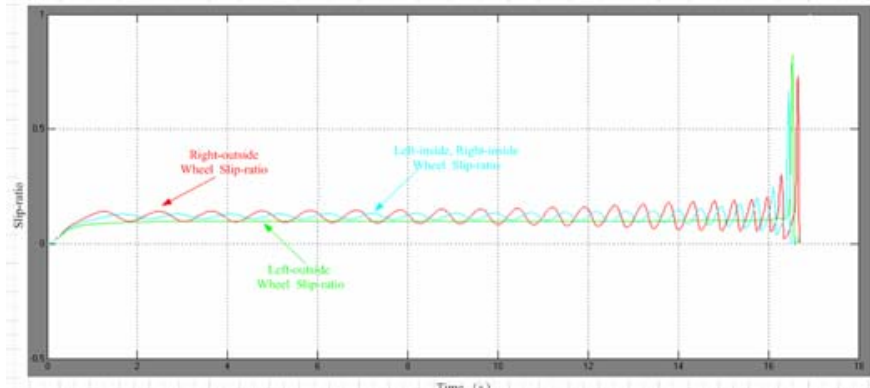

b. Slip-ratio vs. time

Figure 11. Simulation results of different load in left and right

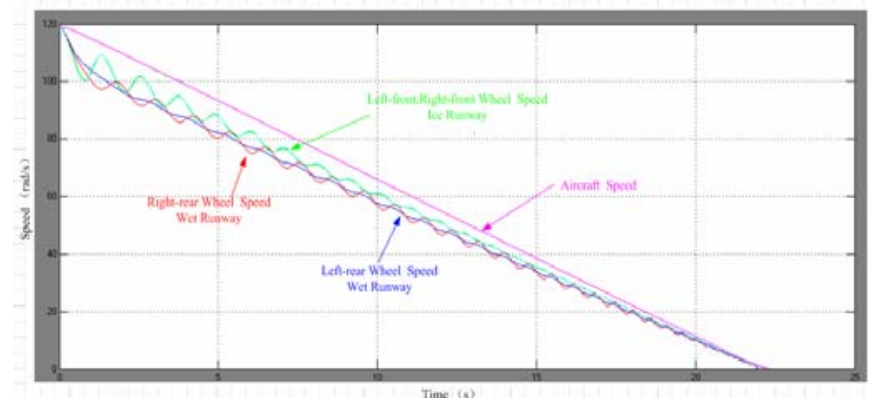

a. Speed vs. time

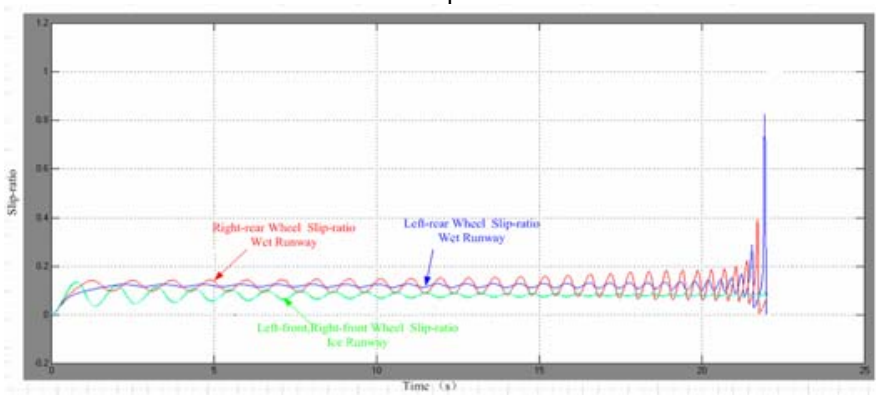

b. Slip-ratio vs. time

Figure 12. Simulation results of different load and runway status

Figure 8-12 shows the simulation results of several common landing states of the multi-wheel aircraft:

1).In case of the same runway and load, the slip-ratio and speed of each braked wheel are highly consistent; 2). Due to the drainage of the front wheel, the front wheel slip-ratio is lower than the rear wheel; 3). The speed and slip-ratio of inside wheel with higher load are more smooth and stable than the outside wheel; 4). Under the different load with non-symmetry, the performances of inside wheel of left and right side are same, the speed and slip-ratio of left outside wheel is most smooth, and the load of right outside wheel with the worst performance is lightest; 5). Under the runway and load are all different, the left and right front wheel is not sensitive to the load difference on the ice runway. The load and runway friction coefficient of left rear wheel are higher than the other wheels, and the wheel speed and slip ratio is relatively stable, followed by the right rear wheel; 6). Comparing to the runway status, the landing loads has little effect on braking time.

The individual wheel fuzzy control based on slip- ratio of muti-wheel braking system can accurately identify the runway status, real-time adjust the control parameters to maintain sliprate in the vicinity of the ideal value. Thus the friction force of runway is furthest utilized, and the braking efficiency is improved, at the same time, the stability and security of aircraft ABS are improved.

\section{CONCLUSION}

The individual wheel fuzzy control mode based on slipratio is adapted to the aircraft muti-wheel braking system. According the different load and runway surface conditions, the control parameters are automatically adjust to take the greatest efficient use of the runway friction. The results also show that the runway status has greater impact on the overall braking performance of aircraft than the load. This paper lays the foundation for determining the multi-wheel aircraft braking characteristics in integrated environment. The crosswind, the nose wheel steering and rudder control, and other related systems will be the next work.

\section{REFERENCES}

[1] FENG Jun, "Development Trend and Key Technologies of Landing Gear of Large Civil Aircraft", Aeronautical Manufacturing Technology, n. 2,pp. 52-56, 2009. (in Chinese)

[2] YUAN Zhao-hui, WANG Yi, YANG Fang., "Application of New Fuzzy Control in Airplanes'Integrated Ground Directional Control System", Computer Simulation, vol.28, n.2, pp.76-79,92, 2011. (in Chinese)

[3] GJB, "GJB3063.General specification of the landing gear system for aircraft", the People's Republic of China National Military Standard, 1997.

[4] SAE, "ARP1070B Design and Testing of Antiskid Brake Control Systems for Total Aircraft Compatibility",U.S.A: Society of Automotive Engineers, Inc.2011.

[5] Gu Hongbin, "A Synthetical Study of Aircraft Ground Handling by Numerical Simulation", Nanjing University of Aeronautics \& Astronautics,Nanjing, China,1999.

[6] Pan Wenting,Kuang Aimin,Feng Yunwen, "Study on the wheel Load Distribution of a Four-wheel Aircraft Landing Gear when Landing at Large Attack Angle", Mechanical Science and Technology for Aerospace Engineering, vol.27, n.5, pp.649-651,2008. (in Chinese)

[7] THOMPSON,Robert,Ian, “aircraft braking system",WIPO Patent No.WO 054715 A1,2007.

[8] LI Sizheng,"Analysis of Aircraft Taxiing-induced Response with Multiple Wheels and Multiple Landing Gears", Northwestern Polytechnic University, Xi'an, China, 2006.

[9] HE Heng,WU Ruixiang, "Improved BP neural network in design of aircraf antiskid braking system", Journal of Beijing University of Aeronautics et Astronautic, vol.10, n.6, pp.561-564,2004. (in Chinese)

[10] YAN Ai-jun, WANG Pu, AN Xiao-hui, "Review of Control Method for Airplane Anitskid Braking System", Control Engineering of China, vol. 15, n.1, pp.1-4, 2008. (in Chinese)

[11] Ioan URSU,Felicia URSU, “A Fuzzy Logic Control Synthesis for An Airplane Antilock-braking System", Proceedings of the ROMANIAN ACADEMY, Series A(page:1-10, Year of Publication: 2004).

[12] Duk-Hyun Park,Burbank,CA. "Optimal Control Design for Aircraft Antiskid Brake Control Systems", US Patent No.0069902A1, 2004. 